\title{
CHANGES IN THE MANAGEMENT OF PATIENTS WITH SEVERE ACUTE PANCREATITIS
}

\author{
Tercio De CAMPOS, Candice Fonseca BRAGA, Laíse KURYURA, Denise HEBARA, \\ José Cesar ASSEF and Samir RASSLAN
}

\begin{abstract}
Background - Severe acute pancreatitis is present in up to $25 \%$ of patients with acute pancreatitis, with considerable mortality. Changes in the management of acute pancreatitis in the last 2 decades contributed to reduce the mortality. Aim - To show the evolution in the management of severe acute pancreatitis, comparing two different approaches. Methods - All patients with severe acute pancreatitis from 1999 to 2005 were included. We compared the results of a retrospective review from 1999 to 2002 (group A) with a prospective protocol, from 2003 to 2005 (group B). In group A severe pancreatitis was defined by the presence of systemic or local complications. In group B the Atlanta criteria were used to define severity. The variables analyzed were: age, gender, etiology, APACHE II, leukocytes, bicarbonate, fluid collections and necrosis on computed tomography, surgical treatment and mortality. Results - Seventy-one patients were classified as severe, 24 in group A and 47 in group B. The mean APACHE II in groups A and B were 10.7 \pm 3.5 and $9.3 \pm 4.5$, respectively. Necrosis was seen in 12 patients (50\%) in group A and in 21 patients (44.7\%) in group B. Half of the patients in group A and two (4.3\%) in group B underwent to pancreatic interventions. Mortality reached $45.8 \%$ in group A and $8.5 \%$ in group B. Conclusion - A specific approach and a prospective protocol can change the results in the treatment of patients with severe acute pancreatitis.
\end{abstract}

HEADINGS - Pancreatitis, acute necrotizing.

\section{INTRODUCTION}

As defined by the Atlanta criteria, severe acute pancreatitis (SAP) is present in up to $25 \%$ of the patients with acute pancreatitis (AP), with mortality of $10 \%-20 \%^{(7,35)}$.

Two phases concerning mortality are described in the course of SAP: the first one is characterized by systemic inflammatory response syndrome (SIRS), and comprises the first 10 days, and the second phase starts in the end of the 2 nd week and is marked by infectious complications $^{(22,24,33)}$.

The early diagnosis and severity assessment have a critical effect in the prognosis of a patient with AP, due to the identification of potentially severe patients, and consequently, the establishment of a proper approach.

Changes in the management of these severe patients in the last decade, such as enteral nutrition, early use of antibiotics, improvement in intensive care unit (ICU) and late operation, contributed to decrease the number of deaths ${ }^{(5,10,15,27,29,30,33,34)}$.

The aim of this study is to show the evolution in the management of patients with SAP, comparing two different approaches.

\section{METHODS}

All patients with SAP from January 1999 to November 2005 admitted in the Emergency Service at Santa Casa of São Paulo, SP, Brazil, were included in this study. Those who have started treatment in other hospitals were excluded.

Clinical signs associated with an increase in serum amylase or lipase of at least three fold defined the diagnosis of AP.

The treatment consisted of fasting, hydration and analgesics. Endoscopic retrograde cholangiopancreatography (ERCP) was performed when the patient with biliary etiology had progressive jaundice or when there was the diagnosis of cholangitis. Surgery was proposed in patients who developed pancreatic infection. The diagnosis of pancreatic infection was confirmed by computed tomography (CT) or fine needle aspiration (FNA). The surgical procedure consisted by removal of infected pancreatic tissue and/or external drainage of infected fluid collection.

The patients were divided into two groups: the first group comprising those treated from January 1999 to December 2002 (group A), which was a retrospective review. The 
second group started in 2003 until November 2005, evaluated with a prospective protocol (group B) approved by the Ethics Committee on Research of the Department of Surgery of the hospital.

In group A, pancreatitis was classified as severe based on the presence of systemic complications, such as hypotension, sepsis, pulmonary or renal failure, or local complications (necrosis or pancreatic infection). Those patients that did not respond to initial treatment were also considered severe. CT was indicated in the severe patients and antibiotics were used "on demand", when there was a suspicious of infection. Parenteral nutritional support was administered to all patients.

In group B the Atlanta criteria were used to assess the severity of AP. The indications for CT were abdominal distension or signs of peritonitis, ultrasound with peri-pancreatic fluid, APACHE II $>8$ and C-reactive protein (CRP) $>150 \mathrm{mg} / \mathrm{L}$. In this group, ciprofloxacin $400 \mathrm{mg} 2 \mathrm{x} /$ day and metronidazole $500 \mathrm{mg} 3 \mathrm{x} /$ day were administered for 10 to 14 days in those patients with local complications, such as necrosis or peri-pancreatic fluid collection. Enteral nutritional was chosen as the preferred way to feed those patients that could not be fed within 96 hours of hospital admission and required nutritional support.

We analyzed patients with SAP and compared group A with group B. The following variables were studied: age, gender, etiology, APACHE II, leukocytes, bicarbonate, fluid collections and necrosis on $\mathrm{CT}$, surgical treatment and mortality.

Chi square and Student's $t$ test were used for statistical analysis, considering $P<0.05$ as significant.

\section{RESULTS}

In this period we analyzed 71 patients with SAP, 24 in group A and 47 in group B. The mean age was $49 \pm 17$ years in group $A$ and $57.6 \pm 14.4$ years in group $\mathrm{B}(P=0.028)$. In group $\mathrm{A}, 17(70.8 \%)$ patients were male, similar to $30(63.8 \%)$ in group $B(0.745)$ (Table 1$)$.

TABLE 1. Comparison of variables in group A and group B

\begin{tabular}{lccc}
\hline Variables & Group A n $=24(\%)$ & Group B n $=47(\%)$ & $P$ \\
\hline Mean age & $49 \pm 17$ & $57.6 \pm 14.4$ & 0.028 \\
Males & $17(70.8)$ & $30(63.8)$ & 0.745 \\
Alcohol etiology & $13(54.2)$ & $20(42.6)$ & 0.499 \\
APACHE II & $10.7 \pm 3.5$ & $9.3 \pm 4.5$ & 0.188 \\
Leucocytes & $15,983 \pm 5,414$ & $13,715 \pm 6,000$ & 0.124 \\
HCO3 < 18 mEq/1 & $6(25)$ & $17(36.2)$ & 0.494 \\
Fluid collections (CT) & $15(62.5)$ & $17(36.2)$ & 0.063 \\
Necrosis (CT) & $12(50)$ & $21(44.7)$ & 0.862 \\
Pancreatic surgery & $12(50)$ & $2(4.3)$ & $<0.001$ \\
Mortality & $11(45.8)$ & $4(8.5)$ & 0.015 \\
\hline
\end{tabular}

The mean APACHE II in groups A and B were, respectively, $10.7 \pm 3.5$ and $9.3 \pm 4.5(P=0.188)$. The leukocytes in group A were 15,983 $\pm 5,414$ and in group B were 13,715 $\pm 6,000$ $(P=0.124)$. CT scan showed fluid collections in 15 patients $(62.5 \%)$ in group A and in $17(36.2 \%)$ in group B $(P=0.063)$. Necrosis was seen in 12 patients $(50 \%)$ in group $A$ and in 21 patients $(44.7 \%)$ in group B $(P=0.862)$. Half of the patients in group A were submitted to pancreatic interventions, while two $(4.3 \%)$ patients in group B needed operation $(P<0.001)$ (Table 1). The reasons for operation are listed in Table 2.

TABLE 2. Reasons for pancreatic operation

\begin{tabular}{lcc}
\hline Reason & Group A (\%) & Group B (\%) \\
\hline Abscess & $6(50)$ & $1(50)$ \\
Infected necrosis & $6(50)$ & 0 \\
Clinical deterioration & 0 & $1(50)$ \\
Total & $12(100)$ & $2(100)$ \\
\hline
\end{tabular}

In group A, 8 patients $(33.3 \%)$ had biliary etiology and 13 patients had alcoholic etiology (54.2\%). In group B, 22 patients (46.8\%) had gallstones, and $15(31.9 \%)$ had alcoholic etiology (Table 3).

TABLE 3. Etiology of SAP

\begin{tabular}{lcc}
\hline Etiology & $\begin{array}{c}\text { Group A (\%) } \\
\mathbf{n}=24\end{array}$ & $\begin{array}{c}\text { Group B (\%) } \\
\mathbf{n}=47\end{array}$ \\
\hline Biliary & $8(33.3)$ & $22(46.8)$ \\
Alcohol & $13(54.2)$ & $15(31.9)$ \\
Other & $3(12.5)$ & $10(21.3)$ \\
\hline
\end{tabular}

The patients in group A did not receive early antibiotics, while 32 patients $(68.1 \%)$ in group B were treated with antibiotics as soon as the diagnosis of necrosis was confirmed.

Mortality was $45.8 \%$ in group A and $8.5 \%$ in group B $(P=0.015)$. Half of deaths in group A and one (25\%) in group $\mathrm{B}$ were due to pancreatic sepsis (Table 4).

TABLE 4. Causes of death

\begin{tabular}{lcc}
\hline Cause & Group A (\%) & Group B (\%) \\
\hline SIRS + MODS & $5(45.5)$ & $3(75)$ \\
Pancreatic sepsis & $6(54.5)$ & $1(25)$ \\
Total & $11(100)$ & $4(100)$ \\
\hline
\end{tabular}

Table 5 compares group A and group B considering the same criteria of severity used in group A to group B. There was a reduction in the number of severe patients in group B from 47 to 30 . It was observed a reduction in patients underwent operative treatment and mortality in group B when compared to group A.

TABLE 5. Comparison of variables in group A and group B, using the same criteria of severity in both groups

\begin{tabular}{lccc}
\hline Variables & Group A $\mathrm{n}=24(\%)$ & Group B $\mathrm{n}=30(\%)$ & $\boldsymbol{P}$ \\
\hline Mean age & $49 \pm 17$ & $56.1 \pm 13.6$ & 0.094 \\
Males & $17(70.8)$ & $19(63.3)$ & 0.771 \\
Alcohol etiology & $13(54.2)$ & $13(43.3)$ & 0.605 \\
APACHE II & $10.7 \pm 3.5$ & $9 \pm 4.9$ & 0.158 \\
Leucocytes & $15,983 \pm 5,414$ & $14,498 \pm 6,752$ & 0.386 \\
HCO3 <18 mEq/L & $6(25)$ & $12(40)$ & 0.384 \\
Fluid collections (CT) & $15(62.5)$ & $17(56.7)$ & 0.877 \\
Necrosis (CT) & $12(50)$ & $21(70)$ & 0.224 \\
Pancreatic surgery & $12(50)$ & $2(6.7)$ & $<0.001$ \\
Mortality & $11(45.8)$ & $4(13.3)$ & 0.019 \\
\hline
\end{tabular}




\section{DISCUSSION}

The reasons for high mortality of SAP despite improvement in the management of these patients have been discussed in the literature $^{(19,33,35)}$. Nevertheless, advances in the last 2 decades contributed to reduce the mortality in SAP from about $50 \%$ to less than $10 \%$ in some referral hospitals ${ }^{(3,8,17)}$. The reduction of mortality in the first phase of the disease occurred mainly due to improvement in ICU treatment, including SIRS management and advances in ventilation strategies ${ }^{(14)}$. However, difficulties regarding the second phase persist, because the variables become multiple, and infection is common.

BANK et al. ${ }^{(3)}$ concluded in a review that the reasons for reduction in mortality in the last 2 decades were: early recognition of severity with prompt therapy, improvement in nutritional support, ERCP, angiography and the use of antibiotics.

In this study, we compared two different strategies in the approach and management of these patients and observed different results that could exemplify what has happened in other centers.

Initially, despite a different approach, systemic parameters, as well as APACHE II score $(P=0.188)$, leukocytosis $(P=0.124)$, bicarbonate less than $18 \mathrm{mEq} / \mathrm{L}(P=0.494)$ and the presence of necrosis $(P=0.747)$ were similar between the groups.

Nevertheless, the Atlanta criteria have been questioned in the last years. BUTER et al. ${ }^{(9)}$, in a prospective observational study found that patients with organ failure that persisted for more than 48 hours had a mortality rate up to $50 \%$; by contrast, patients with organ failure that resolved within 48 hours had a mortality rate of zero. This observation has been confirmed in a larger group of patients recruited across the $\mathrm{UK}^{(19)}$. Therefore, APACHE II may not represent an accurate method of evaluation of severity of these patients, if it would be considered only its value on admission.

Furthermore, a 45 year-old patient, for example, has 2 points higher in APACHE II score than a 44 year-old patient, making the age criterion a controversial point.

It is irrefutable that despite the similarity of the groups in this study, group A had a retrospective evaluation that has known limitations, and probably some patients that were included as severe in group B, would not be considered severe in group A giving a stricter sense of severity in group $\mathrm{A}$.

To clarify this doubt and to answer some methodological issues regarding the comparison of two groups with different approaches, we applied, in addition, the same criteria of severity employed in group $\mathrm{A}$ in patients of group $\mathrm{B}$, demonstrated in Table 5. It was observed a reduction from 47 to 30 in patients considered severe in group B, indicating a stricter criteria of severity used previously to Atlanta classification. This occurred because signs of organic failure and local complications, and not Atlanta criteria were utilized in group A, and in Table 5 also in group B. Atlanta criteria and in particular APACHE II at admission overestimate severity in AP. Interestingly very similar results were observed in Table 5 when compared to Table 1, despite distinct criteria of severity used in group $\mathrm{B}$, especially regarding the reduction in need of operation and mortality in group B when compared with group A in both Tables. Moreover, in Table 1 we observed more fluid collections in group A, although without statistical significance $(62.5 \% \times 36.2 \%$, respectively, $P=0.063)$. This difference regarding fluid collections between groups was over in Table 5.

Considering Table 1 to a more detailed analysis, curiously, the age was different between groups. Patients in group B were 8.6 years older than group A. This difference could be explained by a higher number of patients with alcoholic etiology in group A and more patients with biliary etiology in group B.

Regarding gender, these results are consistent with the literature $^{(1,12)}$. Although gallbladder disease is more frequent in women, men develop AP more often. One of the reasons is the high incidence of alcoholic pancreatitis in men $^{(21)}$. If we analyze all the patients with SAP in both groups, 47 (66.2\%) out of 71 were males.

With regards to etiology, the main cause of AP in group A was alcoholic and in group B was biliary. Some authors relate the etiology of AP to a worse prognosis. LANKISCH et al. ${ }^{(21)}$ in 2003, commented that patients with alcoholic AP were more severe than the others, especially those who arrive in the hospital in a period less than 24 hours due to intense pain. The diagnosis of AP in these alcoholic patients can be difficult due to a frequent normal serum amylase on admission. The key to the diagnosis of AP in those patients is the serum lipase, which is more specific than amylase. Despite a normal amylase, lipase is often elevated in patients with alcoholic etiology and confirms the diagnosis. CT scan may be useful in these situations ${ }^{(31)}$.

Many authors have tried to establish predictors of mortality in SAP and thus, to obtain an improvement in the results. COMPANY et al. ${ }^{(11)}$ in a retrospective study analyzed 67 patients with SAP and obtained a mortality rate of $31.3 \%{ }^{(11)}$. Systemic complications such as renal and pulmonary failure were related to mortality. The high mean age of 69 years old and the high number of patients with necrosis $(55.2 \%)$ could justify the elevated mortality.

In another paper, KONG et al. ${ }^{(20)}$ studied retrospectively 94 patients with SAP, and found $54 \%$ with necrosis and a total of $23.4 \%$ of deaths. They concluded that fatal outcome was predicted by respiratory, cardiovascular and renal failures.

Hence, it is a consensus that the development of systemic complications in a patient with necrosis can lead to a worst prognosis ${ }^{(11,34)}$. Our number of patients is still small to consider an analysis about predictors of mortality, although based on these results and in those described above, it is easy to mention that a more careful approach to patients with SAP, and in particular those with necrosis, results in lower morbidity and mortality. This approach includes appropriate fluid administration, intensive care unit, use of antibiotics and nutritional support, with emphasis to enteral nutrition ${ }^{(2,22,23)}$.

This is the starting point that motivated our new protocol. After that, we observed a change in the need of surgical treatment (50\% to $4.3 \%, P<0.001)$ with a consequent mortality reduction from $45.8 \%$ to $8.5 \%(P=0.015)$. The reduction of surgical treatment need or its postponement plays a critical role in the improvement of the prognosis of these patients. 
The early use of antibiotics in $32(68.1 \%)$ patients in group $\mathrm{B}$ may be associated to the reduction of pancreatic infection and surgical need, and with a lower mortality due to pancreatic sepsis.

There are still some criticisms about the use of antibiotics in necrotizing pancreatitis, considering also the conclusions of the recent German clinical trial that failed to show a reduction in infection of pancreatic necrosis (12\% antibiotics vs $9 \%$ placebo, $P=\mathrm{NS}$ ) or reduction in mortality ( $5 \%$ antibiotics vs $7 \%$ placebo, $P=\mathrm{NS})^{(18)}$. However, $28 \%$ of patients in the group that received antibiotics had their protocol opened, versus $46 \%$ in the placebo group $(P=0.037)$. Furthermore, in the same study, the mean time to open the protocol was 11.5 days in the treatment group and 5 days in the placebo group. Based on these data, it is reasonable to suppose that a group of patients had benefited from receiving early antibiotics. This opinion is the same of other authors ${ }^{(6)}$. Moreover, most of recent guidelines and reviews about the treatment of AP recommend the use of antibiotics in necrotizing $\operatorname{AP}^{(4,9,10,13,22,25,26,32,36,38)}$.

Two new studies regarding the use of antibiotics in AP were published in $2007^{(16,28)}$, but with controversial results and some methodological problems. In a recent review WERNER et al. ${ }^{(37)}$ commented that the final conclusion about antibiotics in AP will remain undefined due to the large number of patients required to this expected study.

The antibiotics in this study (ciprofloxacin and metronidazole) are the same used in the ISENMANN et al. ${ }^{(18)}$ clinical trial, and they were chosen instead of imipenem due to a lower cost in our hospital.

The use of enteral nutrition when necessary is another important factor that may play a role in the improvement of patients in group B. The parenteral route is a potential focus of systemic infection in these patients.

The association of antibiotics and enteral nutrition may justify the reduction of pancreatic sepsis and consequently the need of operation.

However, despite the use of antibiotics, enteral nutrition and improvement in the ICU treatment, another important factor in our opinion that makes a difference in the treatment of these patients is the creation of a "pancreatitis team".

In conclusion, a specific approach and management can improve the results of patients with AP. Due to a more careful evaluation by an uniform team, patients with SAP can be identified earlier, allowing the specific care to be applied in time.

De Campos T, Braga CF, Kuryura L, Hebara D, Assef JC, Rasslan S. Mudanças no manejo de doentes com pancreatite aguda grave. Arq Gastroenterol. 2008;45(3):181-5.

RESUMO - Racional - A pancreatite aguda grave está presente em até $25 \%$ dos doentes com pancreatite aguda, com mortalidade considerável. Mudanças no tratamento da pancreatite aguda nas últimas duas décadas contribuíram para a redução da mortalidade destes doentes. Objetivo - Mostrar a evolução do manejo da pancreatite aguda, comparando duas diferentes abordagens. Métodos - Todos os doentes com pancreatite aguda grave de 1999 a 2005 do Serviço de Emergência da Santa Casa de São Paulo, SP, foram incluídos. Os resultados de uma revisão retrospectiva de 1999 para 2002 (grupo A) foram comparados com um protocolo prospectivo, de 2003 para 2005 (grupo B). No grupo A, a pancreatite grave era definida pela presença de complicações sistêmicas ou locais. No grupo B os critérios de Atlanta foram utilizados para definir a gravidade. As variáveis analisadas foram: idade, sexo, etiologia, APACHE II, leucócitos, bicarbonato, coleções e necrose na tomografia, tratamento cirúrgico e mortalidade. Resultados - Setenta e um doentes foram classificados como graves, 24 no grupo A e 47 no grupo B. A média do APACHE II nos grupos A e B foram 10,7 $\pm 3,5$ e 9,3 \pm 4,5, respectivamente. A necrose foi vista em 12 doentes (50\%) no grupo A e em 21 doentes (44,7\%) no grupo B. Metade dos doentes no grupo A e dois (4,3\%) no grupo B foram submetidos a operação pancreática. A mortalidade foi de $45,8 \%$ no grupo A e $8,5 \%$ no grupo B. Conclusão - Uma abordagem específica e um protocolo prospectivo podem mudar os resultados no tratamento de doentes com pancreatite aguda grave.

DESCRITORES - Pancreatite necrosante aguda. 


\section{REFERENCES}

1. Andersson R, Andersson B, Haraldsen P, Drewsen G, Eckerwall G. Incidence, management and recurrence rate of acute pancreatitis. Scand J Gastroenterol. 2004;39:891-4.

2. Avgerinos C, Delis S, Rizos S, Dervenis C. Nutritional support in acute pancreatitis Dig Dis Sci. 2003;21:214-9.

3. Bank S, Singh P, Pooran N, Stark B. Evaluation of factors that have reduced mortality from acute pancreatitis over the past 20 years. J Clin Gastroenterol. 2002;35:50-60.

4. Bassi C, Falconi M, Talamini G, Uomo G, Papaccio G, Dervenis C, Salvia R, Minelli EB, Pederzoli P. Controlled clinical trial of pefloxacin versus imipenem in severe acute pancreatitis. Gastroenterology. 1998;115:1513-7.

5. Bassi C, Larvin M, Villatoro E. Antibiotic therapy for prophylaxis against infection of pancreatic necrosis in acute pancreatitis. Cochrane Database Syst Rev. 2003:CD002941.

6. Bassi C, Falconi M. Discussion on prophylactic antibiotic treatment in patients with predicted severe pancreatitis: a placebo-controlled, double-blind trial. Gastroenterology. 2004; 127:1015-6.

7. Bradley EL 3rd. A clinically based classification system for acute pancreatitis: summary of the international symposium on acute pancreatitis, Atlanta, Ga, September 11 through 13, 1992. Arch Surg. 1993;128:586-90.

8. Büchler MW, Uhl W, Malfertheiner P, Sarr MG. Acute pancreatitis. In: Büchler MW, Uhl W, Malfertheiner P, Sarr MG, editors. Diseases of the pancreas. Basel: Karger; 2004. p.73.

9. Buter A, Imrie CW, Carter CR, Evans S, McKay CJ. Dynamic nature of early organ dysfunction determines outcome in acute pancreatitis. Br J Surg. 2002;89:298-302.

10. Clancy TE, Benoit EP, Ashley SW. Current management of acute pancreatitis. J Gastrointest Surg. 2005;9:440-52.

11. Company L, Saez J, Martinez J, Aparicio JR, Laveda R, Grino P, Perez-Mateo M. Factors predicting mortality in severe acute pancreatitis. Pancreatology. 2003;3:144-8.

12. Dauphine C, Kovar J, Stabile BE, Haukoos JS, de Virgilio C. Identification of admission values predictive of complicated acute alcoholic pancreatitis. Arch Surg. 2004; 139:978-82.

13. De Campos T, Assef JC, Rasslan S. Questions about the use of antibiotics in acute pancreatitis. World J Emerg Surg. 2006;4:1-20.

14. De Campos T, Deree J, Coimbra R. From acute pancreatitis to end-organ injury: mechanisms of acute lung injury. Surg Infect (Larchmt). 2007;8:107-20.

15. Delcenserie R, Yzet T, Ducroix JP. Prophylactic antibiotics in treatment of severe acute alcoholic pancreatitis. Pancreas. 1996;13:198-201.

16. Dellinger EP, Tellado JM, Soto NE, Ashley SW, Barie PS, Dugernier T, Imrie CW, Johnson CD, Knaebel HP, Laterre PF, Maravi-Poma E, Kissler JJ, SanchezGarcia M, Utzolino S. Early antibiotic treatment for severe acute necrotizing pancreatitis: a randomized, double-blind, placebo-controlled study. Ann Surg. 2007;245:674-83

17. Halonen KI, Leppaniemi AK, Puolakkainen PA, Lundin JE, Kemppainen EA, Hietaranta AJ, Haapiainen RK. Severe acute pancreatitis: prognostic factors in 270 consecutive patients. Pancreas. 2000;21:266-71.

18. Isenmann R, Runzi M, Kron M, Kahl S, Kraus D, Jung N, Maier L, Malfertheiner P, Goebell H, Beger HG, German Antibiotics in Severe Acute Pancreatitis Study Group. Prophylactic antibiotic treatment in patients with predicted severe acute pancreatitis: a placebo-controlled, double-blind trial. Gastroenterology. 2004;126:997-1004.

19. Johnson CD, Abu-Hilal M. Persistent organ failure during the first week as a marker of fatal outcome in acute pancreatitis. Gut. 2004;53:1340-4.
20. Kong L, Santiago N, Han TQ, Zhang SD. Clinical characteristics and prognostic factors of severe acute pancreatitis. World J Gastroenterol. 2004;10:3336-8.

21. Lankisch PG, Blum T, Maisonneuve P, Lowenfels AB. Severe acute pancreatitis: when to be concerned? Pancreatology. 2003;3:102-10.

22. Lillemoe KD, Yeo CJ. Management of complications of pancreatitis. Curr Prob Surg. 1998;35:1-98.

23. Marik PE, Zaloga GP. Meta-analysis of parenteral nutrition versus enteral nutrition in patients with acute pancreatitis. BMJ. 2004;328:1407.

24. McKay CJ, Buter A. Natural history of organ failure in acute pancreatitis Pancreatology. 2003;3:111-4.

25. Nathens AB, Curtis JR, Beale RJ, Cook DJ, Moreno RP, Romand JA, Skerrett SJ, Stapleton RD, Ware LB, Waldmann CS. Management of the critically ill patient with severe acute pancreatitis. Crit Care Med. 2004;32:2524-36.

26. Pancreatic Disease Group, Chinese Society of Gastroenterology \& Chinese Medical Association. Consensus on the diagnosis and treatment of acute pancreatitis. Chin J Dig Dis. 2005;6:47-51.

27. Pederzoli P, Bassi C, Vesentini S, Campedelli A. A randomized multicenter clinical trial of antibiotic prophylaxis of septic complications in acute necrotizing pancreatitis with imipenem. Surg Gynecol Obstet. 1993;176:480-3.

28. Rokke O, Harbitz TB, Liljedal J, Pettersen T, Fetvedt T, Heen LO, Skreden K, Viste A. Early treatment of severe pancreatitis with imipenem: a prospective randomized clinical trial. Scand J Gastroenterol. 2007;42:771-6.

29. Sainio V, Kemppainen E, Puolakkainen P, Taavitsainen M, Kivisaari L, Valtonen V, Haapiainen R, Schroder T, Kivilaakso E. Early antibiotic treatment in acute necrotising pancreatitis. Lancet. 1995;346:663-7.

30. Schwarz M, Isenmann R, Meyer H, Beqer HG. Antibiotic use in necrotizing pancreatitis Results of a controlled study. Dtsch Med Wochenschr. 1997;122:356-61.

31. Smotkin J, Tenner S. Laboratory diagnostic tests in acute pancreatitis. J Clin Gastroenterol. 2002;34:459-62.

32. Takeda K, Takada T, Kawarada Y, Hirata K, Mayumi T, Yoshida M, Sekimoto M, Hirota M, Kimura Y, Isaji S, Koizumi M, Otsuki M, Matsuno S. JPN Guidelines for the management of acute pancreatitis: medical management of acute pancreatitis. J Hepatobiliary Pancreat Surg. 2006;13:42-7.

33. Toouli J, Brooke-Smith M, Bassi C, Carr-Locke D, Telford J, Freeny P, Imrie C, Tandon R; Worky Party of the Program Committee of the Bangkok World Congress of Gastroenterology 2002. Guidelines for the management of acute pancreatitis. J Gastroenterol Hepatol. 2002;17:s15-39.

34. Uhl W, Warshaw A, Imrie C, Bassi C, McKay CJ, Lankisch PG, Carter R, Di Magno E, Banks PA, Whitcomb DC, Dervenis C, Ulrich CD, Satake K, Ghaneh P, Hartwig W, Werner J, McEntee G, Neoptolemos JP, Büchler MW; International Association of Pancreatology. IAP Guidelines for the surgical management of acute pancreatitis. Pancreatology. 2002;2:565-73.

35. Werner J, Hartwig W, Uhl W, Müller C, Büchler MW. Useful markers for predicting severity and monitoring progression of acute pancreatitis. Pancreatology. 2003;3:115-27.

36. Werner J, Feuerbach S, Uhl W, Buchler MW. Management of acute pancreatitis: from surgery to interventional intensive care. Gut. 2005;54:426-36.

37. Werner J, Hartwig W, Buchler MW. Antibiotic prophylaxis: an ongoing controversy in the treatment of severe acute pancreatitis. Scand J Gastroenterol. 2007;42:667-72.

38. Working Party of the British Society of Gastroenterology; Association of Surgeon of Great Britain and Ireland; Pancreatic Society of Great Britain and Ireland; Association of Upper GI Surgeons of Great Britain and Ireland. UK guidelines for the management of acute pancreatitis. Gut. 2005;54(Suppl 3):1-9.

Recebido em 27/8/2007 Aprovado em 12/2/2008. 